Editöre Not

\title{
Konik Işınlı Bilgisayarlı Tomografinin Endodontik Uygulamalarda Kullanımı
}

\section{Use of Cone-Beam Computed Tomography in Endodontic} Applications

Gülsün Akay ${ }^{1}$ (D), Kahraman Güngör ${ }^{2}$

\begin{abstract}
ÖZET
Diş hekimliğinde teşhis ve tedavi planlamasında radyografik muayene oldukça önemlidir. Konik ışınlı bilgisayarlı tomografi maksillofasiyal yapıların üç boyutlu radyografik değerlendirmesine olanak sağlayan bir görüntüleme yöntemidir. Son yıllarda, karmaşık endodontik problemlerin teşhisi ve tedavisi için üç boyutlu görüntülemeye başvurulmaktadır. Bu derlemenin amacı endodontik uygulamalarda konik ışınlı bilgisayarı tomografinin kullanım amaçlarını ve sınırlamalarını araştırmaktır.
\end{abstract}

Anahtar Kelimeler: Endodonti; Konik ışınlı bilgisayarlı tomografi; Radyografi

\begin{abstract}
Radiographic examination is very important for diagnosis and treatment planning in dentistry. Cone-beam computed tomography is an imaging methods that allows three-dimensional radiographic evaluation of maxillofacial structures. In recent years, three dimensional images have been used for the diagnosis and treatment of complex endodontic problems. The aim of this review is to investigate the uses and limitations of cone beam computed tomography in endodontic applications.
\end{abstract}

Keywords: Cone beam computed tomography; Endodontics; Radiography

Makale gönderiliş tarihi: 21.12.2021 ; Yayına kabul tarihi: 22.12.2021

İletişim: Dr. Gülsün Akay

Gazi Üniversitesi, Diş Hekimliği Fakültesi, Ağız, Diş ve Çene Radyolojisi Anabilim Dalı, Bişkek Cd.(8.Cd.) 1.Sk. No:4 06490 Emek/ANKARA

E-posta: akay.gulsun@hotmail.com, gulsunakay@gazi.edu.tr

1 Doç. Dr., Gazi Üniversitesi, Diş hekimliği Fakültesi, Ağız, Diş ve Çene Radyolojisi A.D, Ankara,Türkiye

2 Prof. Dr., Gazi Üniversitesi, Diş hekimliği Fakültesi Ağız, Diş ve Çene Radyolojisi A.D. Ankara, Türkiye 
Endodontik vakaların güvenilir yönetimi için yeterli klinik ve radyolojik tanısal değerlendirme gereklidir. ${ }^{1}$ Doğru tanı koymak için klinik muayene bulgularıyla eşleşen ayrıntılı tanısal görüntüleme bulgularına ihtiyaç vardır. ${ }^{2}$ Radyografik inceleme endodontik problemlerin teşhisinden tedavi planlamasına ve sonuçların değerlendirilmesine kadar bir sürü unsuru oluşturur. Panoramik ve periapikal radyografiler teşhis ve tedavi planlamasında en sık kullanılan görüntüleme yöntemleridir. Ancak, iki boyutlu görüntülerin değerlendirmesinde bazı sınırlamalar mevcuttur. ${ }^{3} \mathrm{Bu}$ sınırlamalar; anatomik yapıların üst üste binmesi ve ilgili bölgede distorsiyon ve magnifikasyon gibi geometrik bozulmaları içerir. Konik ışınlı bilgisayarı tomografi (KIBT) dişlerin ve çevre dokuların üç boyutlu görüntülerini üreterek bu sorunların üstesinden gelebilir. ${ }^{3,4}$

Konik ışınlı bilgisayarlı tomografi maksilla ve mandibulanın anatomik yapılarının farklı düzlemlerde (aksiyal, koronal ve sagital) dijital görüntülenmesini olanak sağlayan bir görüntüleme sistemidir ve diş hekimliğinde kullanım alanı oldukça geniştir. KIBT ile dişlerin ve çevresindeki yapıların üç boyutlu radyografik değerlendirilmesi ile karmaşık endodontik problemlerin teşhisine ve/veya tedavisine yardımcı olması açısından kullanılmıştır. ${ }^{5} 2011$ yılında Amerikan Endodontistler Birliği (AAE) ve Amerikan Oral ve Maksillofasiyal Radyoloji Akademisi (AAOMR) KIBT'nin endodontide kullanımına ilişkin ortak bir rapor-görüş yayınlamışlardır. ${ }^{6}$ Endodontide KIBT kullanımının ancak taramadan elde edilebilecek tanısal bilgilerin radyasyona maruz kalma riskleri de düşünülerek klinisyen tarafından istem yapılmasını önerirler. Ayrıca KIBT asla her hastada her vakada rutin olarak kullanılmamalı ve detaylı bir klinik muayeneden sonra karar verilmelidir. ${ }^{6} \mathrm{Bu}$ derlemenin amacı konik ışınlı bilgisayarlı tomografi görüntülemenin endodontide kullanım alanları ve sınırlamalarının araştırılmasıdır.

\section{KIBT'nin Endodontide Kullanımı}

Literatürde KIBT'nin endodontik kullanımıyla ilgili çok sayıda çalışma mevcuttur. Bu çalışmalarda kök kanal morfolojilerinin incelenmesi, internal-eksternal kök rezorbsiyonlarının tespiti, endodontik cerrahi öncesi planlamalar, horizontal ve vertikal kök kırıklarının tespiti, taşkın materyalin veya kırılmış kanal aletlerinin tespiti ve çevre dokularla olan ilişkisinin incelenmesinde üç boyutlu görüntülemeden yararlanılmıştır. ${ }^{7-13}$ Avrupa Endodontoloji Derneği'nin kılavuzlarında konik ışınlı bilgisayarlı tomografinin sınırlı bir görüntüleme alanı (FOV-field of view) ile belirli endodontik sorunlarda kullanımı önerilmektedir. Bu kullanımlar şu şekilde ifade edilmiştir: ${ }^{14,15}$

a) Belirtiler ve/veya semptomlar spesifik olmadığında ve iki boyutlu görüntülemenin yetersiz olduğu periapikal patoloji tespitinde,

b) Endodontik tedaviden önce dens invaginatus gibi son derece karmaşık kök kanal anatomilerinin değerlendirilmesinde,

c) Geleneksel radyografilerle tam olarak anlaşılamayan dento-alveolar travmanın değerlendirilmesi ve/ veya yönetiminde,

d) Olası tedavi edilmemiş kök kanalları ve/veya perforasyonu gibi önceki tedavi nedenli komplikasyonları olan vakaların cerrahi olmayan yeniden tedavisinde,

e) Klinik olarak tedaviye cevap vereceği düşünülen kök rezorpsiyonunun değerlendirilmesi ve/veya yönetiminde,

f) Cerrahi endodontik tedavide kompleks periradiküler cerrahi öncesinde ilgili bölgenin değerlendirilmesinde,

g) Geniş ölçüde oblitere olmuş kanalların uzamsal konumunun belirlenmesinde,

h) Klinik muayene ve konvansiyonel görüntülemenin yeterli ve kesin olmadığı, kök kırıklarının göstergesi olan periradiküler kemik (ikincil) değişikliklerinin saptanması amacıyla kullanılabilir.

KIBT üç boyutlu görüntüleme gerektiren endodontik problemlerin teşhisi ve/veya yönetimi için günümüzde önemli bir araç haline gelmiştir; ancak dikkatli kullanılmalıdır. ${ }^{14}$

\section{Kök kanal anatomisinin değerlendirilmesi}

Endodontik tedavi için planlamada genellikle karmaşık kök kanal anatomisinin anlaşılması esastır. Endodontik tedavinin başarısı, tüm kök kanallarının erişilebilir, temizlenebilir, şekillendirilebilir ve doldurulabilmesi gerekir. ${ }^{3,16}$ Kanal konfigürasyonunun, seyrinin ve eğriliklerinin değerlendirilmesi ile daha fazla enstrümantasyon, dezenfeksiyon ve obturasyon olasılığının artmasıyla sonuçlanabilir. ${ }^{10}$

Kök kanal anatomisini değerlendirmek için kullanılan iki boyutlu radyografilerin distorsiyon ya da gö- 
rüntülerin üst üste binmesi gibi bazı sınırlamaları mevcuttur. ${ }^{3,10}$ Ayrıca, iki boyutlu görüntüler bazen başarı oranı üzerinde sonuçları olan gerçek kök kanal sayısını tespit etmeye de izin vermeyebilir. ${ }^{17}$ Çok köklü dişlerde bukkal ve lingual/palatinal kökler üst üste biner; bu nedenle periapikal lezyonların gerçek yerini belirlemek ve değerlendirmek daha zor olabilir. Aynı şekilde kök kanal anatomisi de tam olarak anlaşılamayabilir (Resim 1). Kök kanal tedavili dişlerde, radyoopak kanal dolgu materyali, doldurulmamış kanalları da maskeleyebilir. ${ }^{18}$ KIBT iki boyutlu radyografilerin neden olduğu sınırlamaları kaldırarak klinisyene üç boyutlu görüntüleme ile, karmaşık endodontik problemlerin tanı ve tedavi planlamasında önemli bilgi sunar. ${ }^{10}$

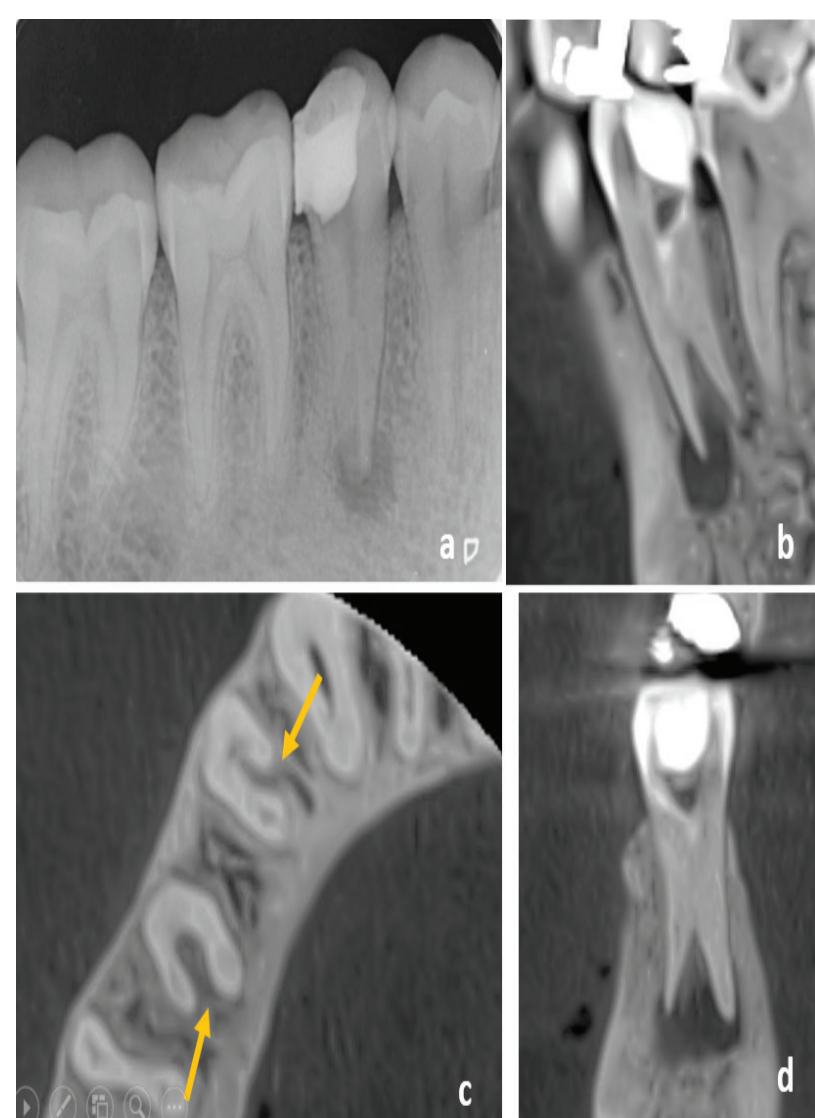

Resim 1. Sağ mandibular 2.premolar dişin atipik kök yapısı ve diş apikalindeki lezyonun; periapikal radyografi görüntüsü (a), konik ışınlı bilgisayarlı tomografi sagital kesit (b), aksiyal kesit (c) ve koronal (d) kesit görüntüsü

KIBT periapikal patoloji ve ekstra kök kanal prevalansı ile ilişkili olarak kök kanal tedavi kalitesini değerlendirmek için çalışmalarda kullanılmıştır. ${ }^{10,19,20}$ Abubara ve ark. ${ }^{20}$ maksiller 1.molar dişlerin meziobukkalde 2.kanal varlığının sadece \%8'inin periapikal radyografi kullanılarak tanımlandığını, KIBT'de ise bu vakaların \%54'ünde meziobukkalde 2.kanal izlendiğini bildirmişlerdir. En sık anatomik varyasyonun izlendiği kanallardan biri mandibular molar dişin distolingual kanalıdır. Baghbani ve ark. ${ }^{21}$ mandibular molar dişlerin distal köklerin belirlenmesinde C-şekilli kanal konfigürasyonunun tanımlanması için beş farklı yöntemi karşılaştırdıkları çalışmalarında, yüksek çözünürlüklü KIBT'nin en yüksek doğruluğu gösterirken periapikal radyografinin en düşük doğruluğu gösterdiğini rapor etmişlerdir. Michetti ve ark. ${ }^{22}$ kök-kanal morfolojisini değerlendirmede KIBT ve histolojik kesitleri karşılaştırdıkları çalışmalarında KIBT görüntüleri ile histolojik kesitler arasında yüksek bir korelasyon bulduklarını bildirmişlerdir.

Kök kanal morfolojisinin üç boyutlu değerlendirilmesinde görüntü çözünürlüğü önemlidir. Kök kanal anatomisinin görünürlüğünü artırmak için voksel boyutunun küçültülmesi ve tarama süresinin uzatılması yüksek çözünürlüklü görüntüleme sağlar. ${ }^{19}$ Ancak, bu faktörlerin yanlış kullanımı radyasyon dozunu potansiyel olarak arttırabilir. Bauman ve ark. ${ }^{23}$ maksiller 1.molar dişlerde ikinci meziobukkal kanalları tespit etmede farklı voksel boyutlarının etkisini değerlendirdiler. Çalışmalarında voksel boyutu $0.4 \mathrm{~mm}$ olduğu görüntülerde \%60 oranında ikinci kanal saptanırken, voksel boyutu $0.125 \mathrm{~mm}$ olduğunda ise bu oranın \%90'a çıktığını gözlemlediler. ${ }^{23}$ Endodontik problemleri değerlendirmede yüksek çözünürlükte görüntüleme gerekir. Görüntülerin kalitesi, FOV'dan daha çok voksel boyutuyla ilgili olsa da, daha küçük FOV'ların seçimi, önemli anatomik yapıların gereksiz yere radyasyona maruz kalmasını önlemede fayda sağlar. ${ }^{12}$ Daha küçük FOV, hastaların radyasyon dozunu azaltır ve KIBT'nin görüntü çözünürlüğünü artırır ve endodontik anatominin araştırılmasında tercih edilir. ${ }^{19}$

Daimi dişlerde ikinci bir kanalın tespiti KIBT taraması ile bir dereceye kadar doğru bir şekilde tanımlanabilir. KIBT kök kanal sisteminin tipini tespit etmedeki duyarlılığının mikro-BT'ye kıyasla \%79 olduğu tahmin edilmektedir. ${ }^{19}$ Ayrıca, bazı çalışmalarda KIBT'nin ana kanalların belirlenmesinde başarıl iken kanalları birbirine bağlayan ve konfigürasyonlarını değiştiren ince anatomik yapıları görüntülemede eksiklikler olduğu ve kanal konfigürasyonu ile ilgili yanlış tanıya yol açtığı da rapor edilmiştir. ${ }^{24}$ Son zamanlarda operasyon mikroskoplarının ekstra kanalların belirlenmesinde KIBT'ye göre daha duyarlı ol- 
duklarına dair çalışmalar yayınlanmaktadır. KIBT'nin iyonize radyasyon riskini karşın bu mikroskoplar önemli bir avantaj sunmaktadır. ${ }^{16}$

\section{Endodontik komplikasyonların değerlendirilmesi}

AAE ve AAOMR'nin endodontide KIBT kullanımı ile ilgili kırılmış endodontik aletler, kalsifiye kanallar ve perforasyonlar gibi endodontik tedavi komplikasyonlarının intra veya postoperatif değerlendirilmesinde kullanılabileceğine dair raporları mevcuttur. ${ }^{6}$ KIBT bu tür intraoperatif kullanımı, endodontik tedavi sırasında gelişebilecek iyatrojenik aksiliklerden kaçınmaya büyük ölçüde yardımcı olabilir. ${ }^{4}$

İntraoral radyografi, endodontik hastalığın yönetimi için tercih edilen görüntüleme tekniğidir, ancak KIBT görüntülemenin, endodontik tanı ve komplikasyonların yönetiminde üstün bir geçerlilik ve güvenilirliğe sahip olduğu görülmektedir. ${ }^{25}$ Endodontik komplikasyonlardan biri de kanal tedavileri sırasında iyatrojenik kök perforasyonlarıdır. Perforasyonun yeri, boyutu ve tespit zamanı, uygun tedavinin seçilmesine, kemik kaybını en aza indirmeye ve tedavi sonucunu tahmin etmeye yardımcı olur; bu nedenle kök perforasyonlarının prognozunu önemli ölçüde etkiler. ${ }^{26}$ Perforasyonun yerinin tam olarak belirlenmesi ayrıca kullanılan onarım malzemesinin tipini belirlemeye de yardımcı olabilir. ${ }^{4}$

Yapılan çalışmalarda kanal tedavisi sırasında iyatrojenik perforasyonların veya kırık aletlerin tespitinde KIBT'nin iki boyutlu radyografilere göre daha iyi sonuçlar verdiği gösterilmiştir. ${ }^{26,27}$ Shokri ve ark. ${ }^{26}$ endodontik tedavili dişlerde kök perforasyonlarının saptanmasında film bazlı periapikal radyografi, dijital fosfor plak (PSP) periapikal radyografisi, KIBT ve multidedektör BT'nin tanısal değerlerini karşılaştırdılar. Periapikal radyografiler veya klinik muayeneye dayalı olarak perforasyonu tespit etmenin mümkün olmadığı kök perforasyonu vakalarında KIBT kullanımının faydalı olduğu sonucuna vardılar. ${ }^{26}$

Literatürde ayrıca KIBT ile yetersiz kök kanal dolgusunun değerlendirildiği çalışmalar da mevcuttur. Periapikal radyografiler ile KIBT görüntülerinin karşılaştırıldığı bir çalışmada KIBT görüntüleme ile köklerin \%46.2'sinde boşluklu kök dolguları tespit edilirken periapikal radyografiler ile tespit edilenlerin neredeyse 3 katı kadar olduğu rapor edilmiştir. ${ }^{28}$

Intraoperatif KIBT taraması, iki boyutlu radyografilerin sınırlamaları nedeniyle tanı veya tedavinin tehlikeye girdiği durumlarda periapikal patoloji, rezorptif defektler ve kök perforasyonları gibi komplikasyonların değerlendirilmesinde önemli bir araç olabilir. Özellikle diğer tanı yöntemlerinin yetersiz olduğu vakalarda intraoperatif komplikasyon durumlarında KIBT küçük FOV ile radyasyon dozu azaltılarak değerli bir tanı aracı olabilir. ${ }^{4}$

\section{Diş anatomisindeki anomaliler}

Farklı anatomiye sahip dişler endodontistler için bir zorluk teşkil edebilir. KIBT incelemesi ile dens invaginatus gibi anormal anatomiye sahip dişlerin tanımlanması, konumu ve değerlendirilmesi sağlanabilir. ${ }^{5}$ Dens invaginatusun belirlenmesinde ayrıntılı bir radyografik inceleme anahtar rol oynar (Resim 2). Ancak konvansiyonel veya dijital periapikal radyog-
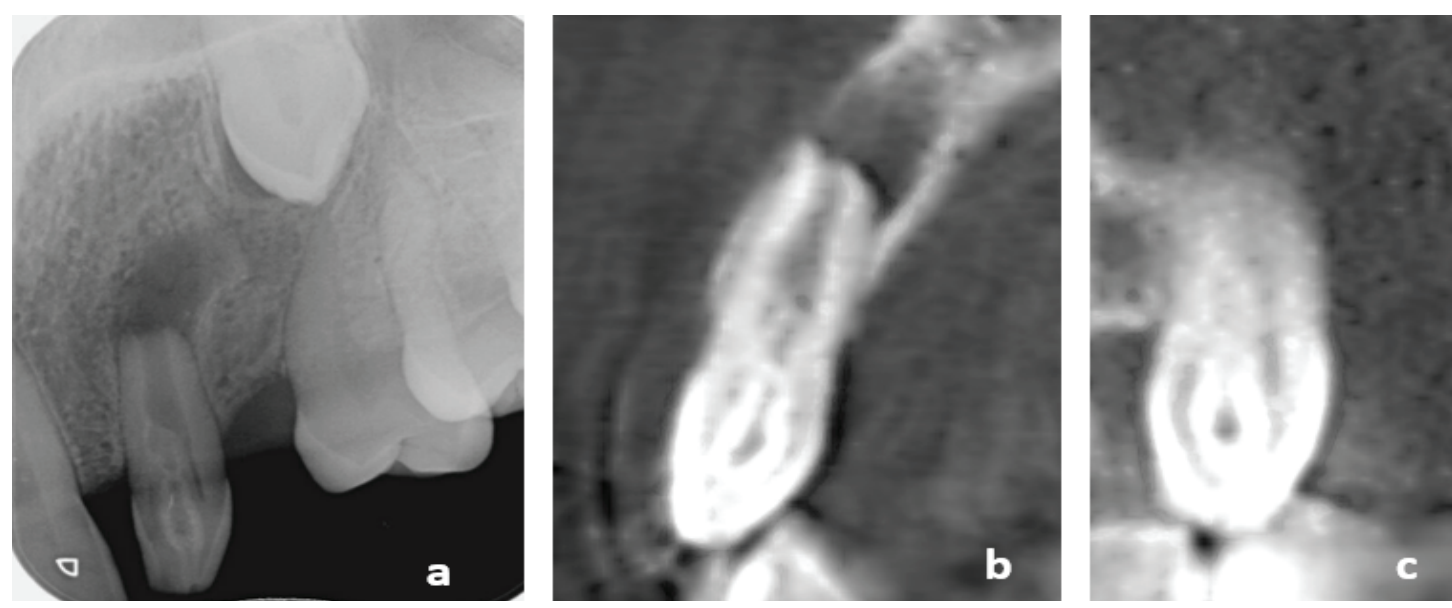

Resim 2. Sol maksiller lateral dişte mevcut dens invaginatus ve ilgili dişin apikal lezyonun ; periapikal radyografisi (a), konik ışınlı bilgisayarlı tomografide sagital (b) ve koronal (c) kesit görüntüsü 
rafiler invajinasyonun tipi ve yaygınlığı ile ilgili detayları ortaya koymayabilir. ${ }^{29} \mathrm{KIBT}$ dens invaginatus ve füzyon gibi anatomik ve morfolojik anomalileri olan dişlerde endodontik tedavi gerektiğinde yararlı bir değerlendirme ve tedavi planlama aracı olabilir. ${ }^{30}$ Avrupa Endodonti derneğinin endodontik tedaviden önce anatomik olarak karmaşık kök kanal sistemlerinin değerlendirilmesinde (dens invaginatus vb) konvansiyonel radyografinin güvenilir tanı için yeterli bilgi sağlamadığı durumlarda küçük bir FOV ile KIBT incelemesi düşünebileceği rapor edilmiştir. ${ }^{15}$

\section{Kök rezorpsiyonları}

Kök rezorpsiyonları dişin sert dokularının kaybıyla ortaya çıkan bir durumdur. Kök rezorpsiyonları kök yüzeyindeki konumlarına göre internal ve eksternal kök rezorpsiyonları olarak iki alt gruba ayrılır (Resim 3 ve 4). ${ }^{31}$ Rezorptif defektlerin doğru teşhis edilmesi zor olabilir ve bu durumda uygun olmayan tedavi prosüdürlerine neden olur. $^{9}$ Kök rezorpsiyonunun tedavisi genellikle karmaşık, zaman alıcı, pahalı ve öngörülemezdir. İki boyutlu bir radyografi ile rezorpsiyonun boyutu ve giriş portallarının görüntülenememesi önemli bir sorundur. Çoğu zaman endodonti, pedodonti, periodontoloji, cerrahi, protez gibi multidisipliner bir uzman ekibi gerektirebilir. ${ }^{32}$ Kök rezorpsiyonlarının tanısında periapikal radyografilere göre KIBT'nin daha üstün olduğunu gösteren ex vivo çalışmalar yayınlanmıştır. ${ }^{33,34}$

Kök rezorpsiyonlarının prognozu erken dönemde tespit edilebilmelerine bağlıdır. ${ }^{35}$ Radyografik olarak internal kök rezorpsiyonu kök kanalları içinde baIonlaşma şeklinde izlenir. Rezorpsiyonlar iyi sınırlı, oval ya da yuvarlak radyolusent alanlar şeklindedir. ${ }^{9}$ Eksternal kök rezorpsiyonları erken dönemde saptanamayabilir. Bunun en önemli nedenlerinden biri rezorpsiyonun lokalizasyonu ve boyutlarıdır. Küçük rezorpsiyon alanlarının teşhisi daha zordur. ${ }^{31}$ Bukkal veya lingual yüzeylerde oluşan lezyonların görülmesi de, iki boyutlu radyografilerde anatomik yapıların üst üste binmesi nedeniyle proksimal yüzeylerdeki lezyonlardan daha zor olabilir. ${ }^{35}$ KIBT'nin eksternal
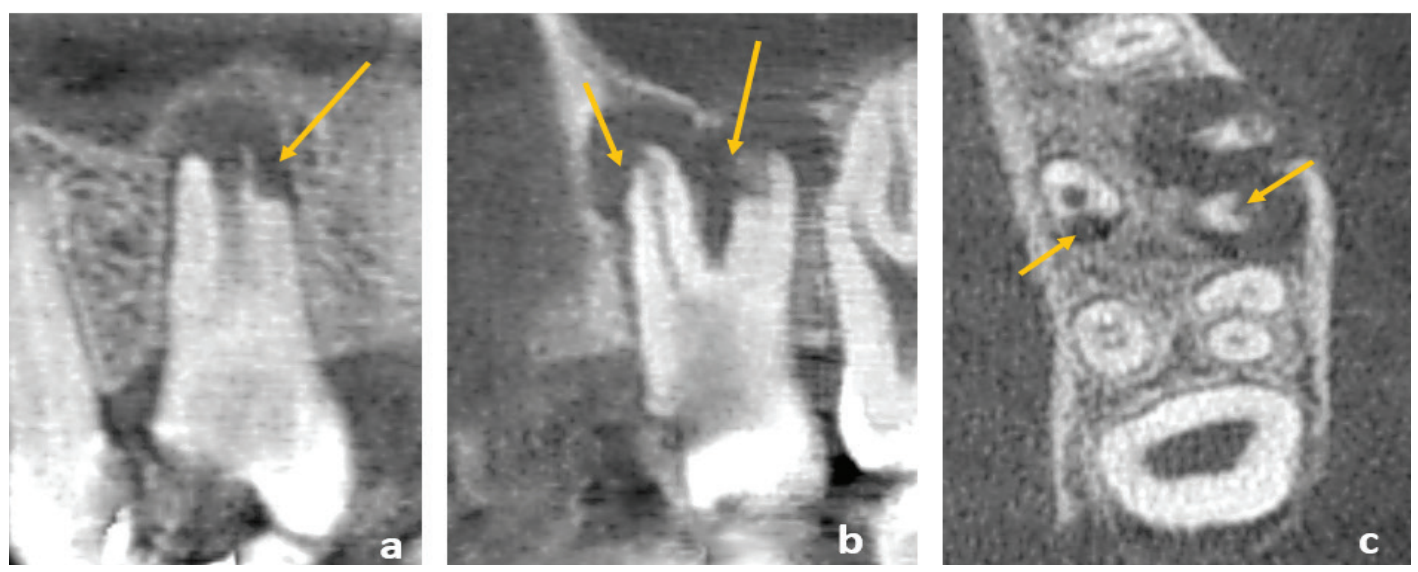

Resim 3. Sol maksiller molar dişin kök apikallerinde izlenen eksternal kök rezorpsiyonu ve lezyonun; konik ışınlı bilgisayarlı tomografide sagital kesit (a ve b) ve aksiyal (c) kesit görüntüsü
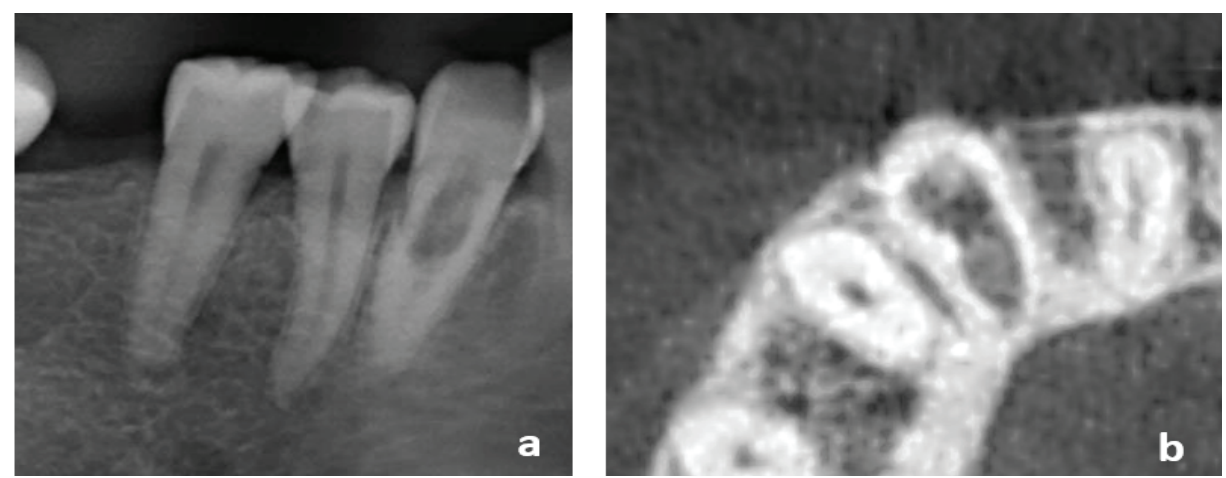

Resim 4. Sol mandibular kanin dişte izlenen internal kök rezorpsiyonun; periapikal radyografi görüntüsü (a), konik ışınlı bilgisayarlı tomografide aksiyal (b) kesit görüntüsü 
kök rezorpsiyonlarında iki boyutlu radyografilerin yetersiz kaldığı lingual/bukkal yüzeylerdeki lezyonların ve çok küçük rezorpsiyonları bile belirleme yetenekleri en önemli avantajlarıdır. ${ }^{35}$

Daimi dişlerde gözlenen rezorpsiyonlar genellikle travma ve kronik pulpa ve/veya periodontal inflamasyondan kaynaklanır. Bernardes ve ark. ${ }^{35}$ intraoral radyograflar ile KIBT görüntülerinde eksternal kök rezorpsiyonun belirlenmesini karşılaştırdılar. İnternal ve eksternal servikal kök rezorpsiyonunu teşhis etmede intraoral radyografinin makul ölçüde doğru olmasına rağmen, KIBT taramaları ile, özellikle apikal üçlüdeki kök rezorpsiyonunun varlığının ve tipinin daha iyi teşhis edildiğini bildirmişlerdir. ${ }^{35}$ Kök rezorpsiyonlarının belirlenmesinde KIBT görüntülerinin voksel boyutu küçüldükçe rezorpsiyon tanısının doğruluğunun arttığı rapor edilmektedir. ${ }^{36}$ Liedke ve ark. ${ }^{37}$ eksternal kök rezorpsiyonunun tespiti için minimum voksel çözünürlüğünün $0.3 \mathrm{~mm}$ olması gerekliliğini vurgulamışlardır. ${ }^{37}$

\section{Dental travma}

Travmatik diş yaralanmalarının tedavisine yönelik çağdaş kılavuzlarda travmadan etkilenmiş bir dişin değerlendirilmesi yapılırken anterior oklüzal radyografinin iki periapikal radyografinin bulgularını desteklemesi gerektiği savunulmaktadır. ${ }^{5}$ Dental kök kırıklarının teşhisi klinik uygulamada karşılaşılan bir zorluktur. Kök fraktürlerinde fragmanlar eğer yer değiştirmediyse travma sonrasında konvansiyonel intraoral radyografiler ile kırıkları görselleştirmek zor olabilir. ${ }^{25,38}$ Çoğu zaman bu kırıklar pulpadan periodontal ligamente kadar uzanır. Kök kırıklarının teşhisinin önemi, çoğunlukla prognozu ile ilgilidir. Geniş kök kırığı olan dişlerin prognozu kötüdür ve çoğu durumda tek olası tedavi seçeneği çekimdir. Bu nedenle, gereksiz ve uygunsuz tedaviden kaçınmak için doğru teşhis şarttır. ${ }^{38}$

Şüpheli bir horizontal kök kırığı tanısında, mobilitenin değerlendirilmesi, yumuşak dokuların palpasyonuna karşı hassasiyet ve ağrının olup olmadığı, etkilenen dişlerin perküsyonu ve pulpa canlılığı ile vitalite testini içeren kapsamlı bir klinik değerlendirme gerekir. ${ }^{39}$ Horizontal kök kırıklarını tespit etmek, özellikle meziyodistal düzlemdeki vertikal kırıklara göre muhtemelen daha kolaydır. ${ }^{25}$ Radyografik bulgularda horizontal kırıklar diş parçalarını ayıran bir veya daha fazla radyolüsent çizgi şeklinde izlenebilir. Tanı için farklı açılarda birden fazla radyografi gerekebilir. ${ }^{39} \mathrm{X}$-ışını kırık düzlemine paralel olduğunda konvansiyonel radyografiler tanı için yardımcı olur. Ancak iki boyutlu görüntülemede komşu yapıların üst üste binmesi nedeniyle kök kırıklarını belirlemek daha zordur. ${ }^{38,40}$

Vertikal kök kırıkları radyolojik ve klinik olarak belirlenmesi zor vakalardır. Kök kırıkları, pulpası etkilenmemiş vital dişlerde veya endodontik tedavi görmüş dişlerde meydana gelebilir. Endodontik tedavi görmüş dişlerde kök kanal dolgusu işlemleri sırasında aşırı lateral kondenzasyon kuvveti ve endodontik postların kama etkisi yaratması kök kırıklarınn gelişmesine neden olabilir. ${ }^{38,40}$ Kök kanal dolgusu mevcut dişlerde kök kırıklarını belirlemek daha zordur. ${ }^{40} \mathrm{Be}$ chara ve ark. ${ }^{40}$ çalışmalarında endodontik olarak tedavi edilen köklerin kök fraktürünü göstermede fosfor plak görüntülerinin büyük FOV ile çekilen KIBT görüntülerinden daha doğru sonuç verdiğini rapor etmişlerdir. Ayrıca yazarlar fosfor plakların küçük bir FOV ile çekilen KIBT kadar kök kırıklarını belirlemede iyi olduğunu da göstermişlerdir. ${ }^{40}$
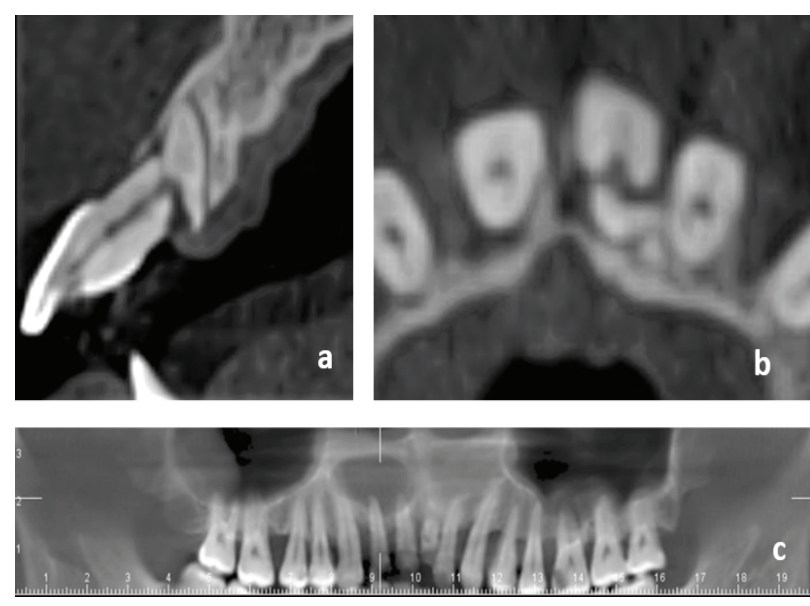

Resim 5. Sol maksiller santral kesici dişte izlenen fraktür; konik ışınlı bilgisayarlı tomografide sagital (a) kesit, aksiyal (b) kesit görüntüsü, rekonstrükte edilmiş panoramik görünümü (c)

İki boyutlu intraoral radyografi, kök kırıklarını teşhis etmek için kullanılan en yaygın görüntüleme aracıdır. Son zamanlarda, KIBT taramaları kök kırıklarını değerlendirmek için kullanılmaktadır (Resim 5). Fraktür hattının belirlenmesinde üç boyutlu görüntülemede voksel boyutu önemli bir faktördür. Voksel boyutu görüntünün çözünürlüğünü belirler. Voksel boyutu küçüldükçe vertikal kök kırıklarının yüksek doğruluk oranları ile belirlenebilirliğinin arttığına dair çalışmalar mevcuttur. ${ }^{36}$ Ancak daha küçük voksel boyutları daha yüksek çözünürlükle sonuçlansa da, sinyal 
gürültü oranının azalmasına ve sonuç olarak görüntü kalitesinin düşmesine neden olabilir ve bu da kök kırıklarının saptanmasını etkileyebilir. ${ }^{41} \mathrm{KIBT}$ 'de voksel boyutu ve kontrast kök kanal dolgusu mevcut dişlerde fraktür hattının belirlenmesinde etkilidir. Özellikle bu tür dişlerde dolgu materyalinin neden olduğu artefakt nedeniyle (ışın sertleşmesi) şıısal çizgilenmeler kırık hattı gibi izlenebilir ve yanlış tanıya götürebilir. ${ }^{42}$ Hassan ve ark. ${ }^{42}$ çalışmalarında KIBT ve periapikal görüntülerde vertikal kök kırıklarını belirleme etkinlikleri ile kök kanal dolgusunun kırık görünürlüğü üzerine etkisini değerlendirdiler. KIBT görüntüleme opak dolgu materyali varlığında vertikal kök kırıklarını saptamada periapikal radyograflardan genel olarak daha yüksek bir doğrulukta olduğunu buldular. ${ }^{42}$

\section{Periapikal patolojilerin değerlendirilmesi}

Radyografilerde lezyonu belirlemede yüksek oranda etkileyen faktörlerden biri kemik kalınlığıdır. İki boyutlu radyografilerde periapikal lezyonların erken dönemde saptanamamasının nedenlerden biri üç boyutlu anatomik bir yapının iki boyutlu görüntü şeklinde elde edilmesi ve anatomik yapıların üst üste binmesidir. ${ }^{43}$ Bir intraoral radyografta, sadece kemik medüller komponentini tutan lezyonlar, yeterli kontrast oluşturamadığı için radyolusent alana kadar uzanan kortikal hatlar nedeniyle fark edilmeden atlanılabilir. ${ }^{17}$ KIBT'nin apikal periodontitis tanısı için periapikal radyografilere göre daha yüksek duyarlılık ve özgüllük gösterdiği bildirilmiştir. ${ }^{18}$ Lamina duradaki düzensizlik ve periodontal ligament boşluğunun genişlemesi periapikal patolojinin en erken belirtisidir. Bu yüzden, endodontide kullanılan herhangi bir KIBT görüntüleme sisteminin optimal çözünürlüğünün $200 \mu$ m'yi (periodontal ligamentin ortalama genişliğini) aşmaması önerilir. ${ }^{3}$

Periapikal durumun önceden bilindiği referans standartlarla yapılan ex vivo çalışmaların sonuçlarında, KIBT'nin periapikal periodontitisi saptamak için periapikal radyograflardan daha doğru sonuçlar verdiği rapor edilmiştir. ${ }^{8,9,43-45 .}$ Patel ve ark. ${ }^{11}$ primer kanal tedavisi planlanan ilgili diş köklerinin sadece \%20'sinde periapikal radyografta periapikal lezyon belirken KIBT kullanıldığında bu oranın \%48 olduğunu bildirmişlerdir. Lo Giudice ve ark. ${ }^{17}$ endodontik prosedürlerde kullanılan konvansiyonel intraoral radyografiler ile KIBT'nin doğruluğunu değerlendirmişlerdir. Çalış- malarında KIBT ile vakaların \%46'sında radyolüsent bir alan tespit edilirken, intraoral radyografilerde sadece \%18'inde pozitif çıktı̆ı̆ını, periapikal radyolusensi ile ilişkili olsun veya olmasın, endodontik bir patolojinin veya yanlış bir tedavinin varlığının intraoral radyografilerde her zaman görülmediğini vurgulamışlardır. ${ }^{17} \mathrm{KIBT}$ ağrı ile başvuran, tedavi edilmemiş veya daha önce kanal tedavisi görmüş bir dişle ilişkili zayıf lokalize semptomları olan ve geleneksel görüntüleme ile tanımlanan hiçbir patoloji kanıtı olmayan hastalarda da kullanılabilir. ${ }^{3}$

\section{Endodontik Cerrahi Öncesi Değerlendirme}

Endodontik cerrahi işlemleri öncesinde tedavi planlaması amacıyla KIBT görüntüleme önerilmiştir. ${ }^{25}$ KIBT endodontik cerrahi vakalarında diagnostik yardım ve tedavi planlanması açısından yararlı bir görüntüleme aracı olduğu savunulmuştur. ${ }^{5,30,46}$ Dişleri çevreleyen alveoler kemiğin ve içinde bulunduğu anatomik yapılar bölgesel ve bireysel olarak varyasyonlar gösterebilir, bu durum endodontik cerrahi işlemlerini daha komplike hale getirir. KIBT anatomik yapıların ve aksesuar kanalların yerini ve periapikal lezyonun boyutu ile komşu anatomik yapılara uzaklığını belirlemede güvenilir ve etkili bir yöntem sağlar. ${ }^{5,47} \mathrm{Apikal}$ periodontitisin saptanması ve etkilenen köklerin belirlenmesi ile cerrah köke spesifik işlemi gerçekleştirir, etkilenmeyen köklerin dentin ve alveoler kemiğin çıkarılması da engellenir. ${ }^{48}$ Böylece prosüdür daha kolaylıkla gerçekleştirilerek hasta konforu sağlanır, maliyet düşürülür. KIBT ile lezyonun anatomik yapılarla ilişkisi belirlenir, kemikte ekspansiyona ya da perforasyona neden olup olmadığı da doğru bir şe-

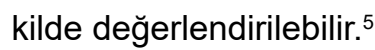

KIBT endodontik cerrahi uygulamalarda rutin olarak kullanılan bir görüntüleme yöntemi değildir. Çok köklü dişler gibi karmaşık cerrahi prosüdüründe ve kök uçlarının maksiller sinüs veya inferior mandibular kanal gibi önemli anatomik yapılarla komşulukta olduğu ve periapikal radyografilerle tam belirlenemediği durumlarda cerrahi öncesi KIBT görüntülenmesi önerilmektedir. ${ }^{5}$

\section{KIBT'nin Endodonti Uygulamalarındaki Limitasyonları}

KIBT ile görüntülemeye kapsamlı bir klinik muayene ve uygun konvansiyonel radyograflar alınıp değerlendirildikten sonra karar verilmelidir. ${ }^{15}$ KIBT en 
önemli dezavantajı periapikal radyografilere göre radyasyon dozunun daha fazla olmasıdır. İyonlaştırıcı radyasyon yayan herhangi bir radyografi cihazında olduğu gibi, ALADA (As Low As Diagnostically Achievable) ilkesi dikkate alınmalı ve KIBT çekim endikasyonu verirken faydaları risklerinden daha ağır basmalıdır. ${ }^{15}$ Ayrıca, iyonlaştırıcı radyasyonun potansiyel etkilerine karşı daha duyarlı olan gruplarda (çocuklar ve ergenlerde) özellikle dikkatli olunmalıdir. $^{49}$

Endodontide KIBT görüntüleri için optimal çözünürlük, vakaya göre değişkenlik gösteririr. Ancak; endodontinin çoğu yönü küçük yapıların görüntülenmesini içerir. ${ }^{3}$ Görüntü kalitesi FOV, voksel boyutu, tüp voltajı gibi bazı faktörlerden etkilenir. ${ }^{25}$ Farklı çözünürlük ayarları ile alınan KIBT görüntüleri arasında tanısal doğruluk açısından fark bulunmazsa, görüntülemede düşük dozlar seçilmelidir. Bununla birlikte, radyasyon dozu görüntüleme cihazına özgüdür ve büyük ölçüde değişebilir. ${ }^{25}$

KIBT görüntü doğruluğunu etkileyen faktörlerden biri de artefaktlara karşı oldukça hassas olmasıdır. Hastaya ve tarayıcıya bağı ırtefaktlar, konik ışın etkisi gibi kullanılan KIBT sistemine özgü artefaktlar ve ışın sertleşmesi önemli artefaktlardır. ${ }^{3}$ Yüksek yoğunluklu komşu yapı ve malzemelerin neden olduğu saçılma ve ışın sertleşmesi görüntü kalitesini ve üç boyutlu görüntülerin doğruluğunu etkiler. ${ }^{25} \mathrm{KIBT}$ 'nin metalik restorasyonların (örneğin, amalgam restorasyonlar, metal postlar ve/veya kronlar ve implantlar) hatta güta-perkanın varlığı dolayısıyla kök kanal anatomisinin ayrıntılarını, kök rezorpsiyonu ve kök kırıkları gibi ilgili patolojilerin izlenmesini engeleyebilecek radyografik artefaktlara neden olabilir. ${ }^{25}$

\section{SONUÇ}

Dental uygulamalarda tüm radyolojik görüntüleme yöntemlerinde olduğu gibi hastaya sağlayacak yarar ve zarar dengesini düşünülerek çekim endikasyonu verilmelidir. Diagnostik açıdan fayda sağlayacağını düşündügümüz vakalarda da ALADA (As Low As Diagnostically Achievable) prensibine dikkat edilmelidir. KIBT endikasyonunda, özellikle çocukların yetişkinlere göre daha fazla risk altında olduğu düşünülmelidir. ${ }^{39} \mathrm{KIBT}$ çekiminde mümkün olan en küçük FOV, küçük voksel boyutu ve en düşük $m A$ ayarı seçilerek en kısa pozlama süresi kullanılarak KIBT taraması yapılmalıdır. ${ }^{6}$ Günümüzde Avrupa Endo- dontoloji Derneği'nin, Amerikan Endodontistler Birliği (AAE) ve Amerikan Oral ve Maksillofasiyal Radyoloji Akademisi (AAOMR) gibi derneklerin KIBT'nin endodontide kullanımına ilişkin hazırlamış oldukları güncel kılavuzlar takip edilmelidir.

\section{KAYNAKLAR}

1. Bueno MR, Estrela C, Granjeiro JM, Estrela MRA, Azevedo BC, Diogenes A. Cone-beam computed tomography cinematic rendering: clinical, teaching and research applications. Braz Oral Res 2021;35:024.

2. Krug R, Connert T, Beinicke A, Soliman S, Schubert A, Kiefner $P$, et al. When and how do endodontic specialists use cone-beam computed tomography? Aust Endod J 2019;45:365-72.

3. Scarfe WC, Levin MD, Gane D, Farman AG. Use of cone beam computed tomography in endodontics. Int $\mathrm{J}$ Dent 2009;2009:634567.

4. Ball RL, Barbizam JV, Cohenca N. Intraoperative endodontic applications of cone-beam computed tomography. J Endod 2013;39:548-57.

5. Patel S, Brown J, Pimentel T, Kelly RD, Abella F, Durack C. Cone beam computed tomography in Endodontics - a review of the literature. Int Endod J 2019;52:1138-52.

6. American Association of Endodontists; American Academy of Oral and Maxillofacial Radiology. Use of cone-beam computed tomography in endodontics Joint Position Statement of the American Association of Endodontists and the American Academy of Oral and Maxillofacial Radiology. Oral Surg Oral Med Oral Pathol Oral Radiol Endod 2011;111:234-7.

7. Mota de Almeida FJ, Hassan D, Nasir Abdulrahman G, Brundin $\mathrm{M}$, Romani Vestman N. CBCT influences endodontic therapeutic decision-making in immature traumatized teeth with suspected pulp necrosis: a before-after study. Dentomaxillofac Radiol 2021:20200594.

8. Ahlowalia MS, Patel S, Anwar HM, Cama G, Austin RS, Wilson $\mathrm{R}$, et al. Accuracy of CBCT for volumetric measurement of simulated periapical lesions. Int Endod J 2013;46:538-46.

9. Patel S, Dawood A, Wilson R, Horner K, Mannocci F. The detection and management of root resorption lesions using intraoral radiography and cone beam computed tomography - an in vivo investigation. Int Endod J 2009;42:831-8.

10. Patel S, Patel R, Foschi F, Mannocci F. The Impact of different diagnostic imaging modalities on the evaluation of root canal anatomy and endodontic residents' stress levels: A clinical study. J Endod 2019;45:406-13.

11. Patel S, Wilson R, Dawood A, Mannocci F. The detection of periapical pathosis using periapical radiography and cone beam computed tomography - part 1: pre-operative status. Int Endod J 2012;45:702-10.

12. de Freitas JV, Baratto-Filho F, Coelho BS, Tomazinho FSF, Crozeta BM, de Sousa Neto MD, et al. Efficacy of different cone- 
beam computed tomographic protocols in the identification of mesiobuccal canals of maxillary first molars: A tomographic and ex vivo study. J Endod 2017;43:810-5.

13. McClammy TV. Endodontic applications of cone beam computed tomography. Dent Clin North Am 2014;58:545-59.

14. Patel S, Brown J, Semper M, Abella F, Mannocci F. European Society of Endodontology position statement: Use of cone beam computed tomography in Endodontics: European Society of Endodontology (ESE) developed by. Int Endod J 2019;52:1675-8.

15. European Society of Endodontology, Patel S, Durack C, Abella F, Roig M, Shemesh H, et al. European Society of Endodontology position statement: the use of $\mathrm{CBCT}$ in endodontics. Int Endod $\mathrm{J}$ 2014;47:502-4.

16. Baratto Filho F, Zaitter $S$, Haragushiku GA, de Campos EA, Abuabara A, Correr GM. Analysis of the internal anatomy of maxillary first molars by using different methods. J Endod 2009;35:337-42.

17. Lo Giudice R, Nicita F, Puleio F, Alibrandi A, Cervino G, Lizio AS, et al. accuracy of periapical radiography and CBCT in endodontic evaluation. Int J Dent 2018;2018:2514243.

18. Davies A, Mannocci F, Mitchell P, Andiappan M, Patel S. The detection of periapical pathoses in root filled teeth using single and parallax periapical radiographs versus cone beam computed tomography - a clinical study. Int Endod J 2015;48:582-92.

19. Aung NM, Myint KK. Diagnostic accuracy of CBCT for detection of second canal of permanent teeth: a systematic review and meta-analysis. Int J Dent 2021;2021:1107471.

20. Abuabara A, Baratto-Filho F, Aguiar Anele J, Leonardi DP, Sousa-Neto MD. Efficacy of clinical and radiological methods to identify second mesiobuccal canals in maxillary first molars. Acta Odontol Scand 2013;71:205-9.

21. Baghbani A, Bagherpour A, Ahmadis $Z$, Dehban A, Shahmohammadi R, Jafarzadeh $\mathrm{H}$. The efficacy of five different techniques in identifying $\mathrm{C}$-shaped canals in mandibular molars. Aust Endod J 2021;47:170-7.

22. Michetti J, Maret D, Mallet JP, Diemer F. Validation of cone beam computed tomography as a tool to explore root canal anatomy. J Endod 2010;36:1187-90.

23. Bauman R, Scarfe W, Clark S, Morelli J, Scheetz J, Farman A. Ex vivo detection of mesiobuccal canals in maxillary molars using СВCT at four different isotropic voxel dimensions. Int Endod J 2011;44:752-8.

24. Ordinola-Zapata R, Bramante CM, Versiani MA, Moldauer BI, Topham G, Gutmann JL, et al. Comparative accuracy of the Clearing Technique, СBCT and Micro-CT methods in studying the mesial root canal configuration of mandibular first molars. Int Endod J 2017;50:90-6.

25. Venskutonis T, Plotino G, Juodzbalys G, Mickeviciene L. The importance of cone-beam computed tomography in the management of endodontic problems: a review of the literature. $\mathrm{J}$ Endod. 2014;40:1895-901.
26. Shokri A, Eskandarloo A, Noruzi-Gangachin M, Khajeh S. Detection of root perforations using conventional and digital intraoral radiography, multidetector computed tomography and cone beam computed tomography. Restor Dent Endod 2015;40:1090148.

27. Young GR. Contemporary management of lateral root perforation diagnosed with the aid of dental computed tomography. Aust Endod J 2007;33:112-8.

28. Liang YH, Li G, Wesselink PR, Wu MK. Endodontic outcome predictors identified with periapical radiographs and cone-beam computed tomography scans. J Endod 2011;37:326-31.

29. Teixido $M$, Abella F, Duran-Sindreu $F$, Moscoso $S$, Roig M. The use of cone-beam computed tomography in the preservation of pulp vitality in a maxillary canine with type 3 dens invaginatus and an associated periradicular lesion. J Endod 2014;40:1501-4.

30. Durack $C$, Patel $S$ Cone beam computed tomography in endodontics. Braz Dent J 2012;23:179-91.

31. Durack C, Patel S, Davies J, Wilson R, Mannocci F. Diagnostic accuracy of small volume cone beam computed tomography and intraoral periapical radiography for the detection of simulated external inflammatory root resorption. Int Endod J 2011;44:136-47.

32. Cohenca N, Simon JH, Mathur A, Malfaz JM. Clinical indications for digital imaging in dento-alveolar trauma. Part 2: root resorption. Dent Traumatol 2007;23:105-13.

33. Deliga Schroder AG, Westphalen FH, Schroder JC, Fernandes A, Westphalen VPD. Accuracy of digital periapical radiography and cone-beam computed tomography for diagnosis of natura and simulated external root resorption. J Endod 2018;44:1151-8.

34. Creanga AG, Geha H, Sankar V, Teixeira FB, McMahan CA Noujeim M. Accuracy of digital periapical radiography and conebeam computed tomography in detecting external root resorption. Imaging Sci Dent 2015;45:153-8.

35. Bernardes RA, de Paulo RS, Pereira LO, Duarte MA Ordinola-Zapata R, de Azevedo JR. Comparative study of cone beam computed tomography and intraoral periapical radiographs in diagnosis of lingual-simulated external root resorptions. Dent Traumatol 2012;28:268-72.

36. Wenzel A, Haiter-Neto F, Frydenberg M, Kirkevang LL. Variable-resolution cone-beam computerized tomography with enhancement filtration compared with intraoral photostimulable phosphor radiography in detection of transverse root fractures in an in vitro model. Oral Surg Oral Med Oral Pathol Oral Radiol Endod 2009;108:939-45.

37. Liedke GS, da Silveira HED, da Silveira HLD, Dutra V, de Figueiredo JAP. influence of voxel size in the diagnostic ability of cone beam tomography to evaluate simulated external root resorption. J Endodont 2009;35:233-5.

38. Wang $P$, Yan XB, Lui DG, Zhang WL, Zhang Y, Ma XC Detection of dental root fractures by using cone-beam computed tomography. Dentomaxillofac Radiol 2011;40:290-8.

39. May JJ, Cohenca N, Peters OA. Contemporary management 
of horizontal root fractures to the permanent dentition: diagnosis-radiologic assessment to include cone-beam computed tomography. Pediatr Dent 2013;35:120-4.

40. Bechara B, McMahan CA, Noujeim M, Faddoul T, Moore WS, Teixeira FB, et al. Comparison of cone beam CT scans with enhanced photostimulated phosphor plate images in the detection of root fracture of endodontically treated teeth. Dentomaxillofac Radiol 2013;42:20120404.

41. Amintavakoli N, Spivakovsky S. Reliability of CBCT diagnosing root fractures remains uncertain. Evid Based Dent 2017;18:23.

42. Hassan B, Metska ME, Ozok AR, van der Stelt $P$, Wesselink $P R$. Detection of vertical root fractures in endodontically treated teeth by a cone beam computed tomography scan. J Endod 2009;35:719-22.

43. Sogur E, Baksi BG, Grondahl HG, Lomcali G, Sen BH. Detectability of chemically induced periapical lesions by limited cone beam computed tomography, intra-oral digital and conventional film radiography. Dentomaxillofac Radiol 2009;38:458-64.
44. Patel S, Dawood A, Whaites E, Pitt Ford T. New dimensions in endodontic imaging: part 1. Conventional and alternative radiographic systems. Int Endod J 2009;42:447-62.

45. Liang YH, Jiang L, Gao XJ, Shemesh H, Wesselink PR, Wu MK. Detection and measurement of artificial periapical lesions by cone-beam computed tomography. Int Endod J 2014;47:332-8.

46. Tsurumachi T, Honda K. A new cone beam computerized tomography system for use in endodontic surgery. Int Endod $J$ 2007;40:224-32.

47. Bornstein MM, Bingisser AC, Reichart PA, Sendi P, Bosshardt $\mathrm{DD}$, von Arx T. Comparison between radiographic (2-dimensional and 3-dimensional) and histologic findings of periapical lesions treated with apical surgery. J Endod 2015;41:804-11.

48. Kraus RD, von Arx T, Gfeller D, Ducommun J, Jensen SS. Assessment of the nonoperated root after apical surgery of the other root in mandibular molars: a 5-year follow-up study. J Endod 2015;41:442-6.

49. Theodorakou C, Walker A, Horner K, Pauwels R, Bogaerts R, Jacobs $R$, et al. Estimation of paediatric organ and effective doses from dental cone beam CT using anthropomorphic phantoms. $\mathrm{Br}$ J Radiol 2012;85:153-60. 